\title{
Revisión histórica de los hongos psilocibios
}

\author{
Historical review of psilocybin mushrooms \\ Gilberto Palma Ramírez ${ }^{a}$, Diana Laura Pérez Sánchez ${ }^{b}$, \\ Monserrat Hernández Hernández ${ }^{c}$ y Rocío Rodríguez Ramírez ${ }^{d}$
}

\begin{abstract}
:
Psilocybin mushrooms have been consumed in practically all over the world by various human groups at the dawn of their cultures, in times that roll back into a distant past. Apparently, they evolved as a chemical weapon to defend against insects and other predators, however psilocin is harmless in toxicological terms for us, what it would really be inducing are expanded states of consciousness, leading in ancient times to link this effect with what sacred. Psilocybin mushrooms have been used as an oracle, consulting room, divination and treatment. Today they went from being sacred, to being feared, persecuted, hidden, today desecrated and vulgarized in medicine or simple recreation. Mexico has a great mycocultural legacy which is of the utmost importance to preserve.
\end{abstract}

Keywords:

Psilocybin mushrooms, expanded states of consciousness, mycocultural legacy

\section{Resumen:}

Los hongos psilocibios han sido consumidos en prácticamente todo el mundo por diversos grupos humanos en los albores de sus culturas, en tiempos que se retrotraen en un pasado distante. Al parecer evolucionaron como un arma química para defenderse de los insectos y demás depredadores, sin embargo, la psilocina es inocua en términos toxicológicos para nosotros, lo que realmente estaría induciendo son estados expandidos de consciencia, dando lugar en la antigüedad a vincular este efecto con lo sagrado. Los hongos psilocibios han sido utilizados como oráculo, consultorio, adivinatorio y tratamiento. En la actualidad pasaron de ser sagrados, a ser temidos, perseguidos, ocultados, hoy profanados y vulgarizados en medicina o simple recreación. México tiene un gran legado micocultural el cual es de suma importancia preservar.

\section{Palabras Clave:}

Hongos psilocibios, estados expandidos de consciencia, legado micocultural

\section{Introducción}

Los hongos divergieron de los Chytridiomycota hace aproximadamente 550 millones de años y las plantas invadieron el medio terrestre, hace aproximadamente 440 millones de años, además los Ascomycota se separaron de los Basidiomycota ${ }^{(9)}$.

En los Basidiomycota las construcciones celulares en sistemas hifales y basidiocarpos es la expresión de una larga historia evolutiva. Como eucariotas heterotróficos,

\footnotetext{
a Autor de correspondencia, Universidad Autónoma del Estado de Hidalgo, Instituto de Ciencias de la Salud, Área Académica de Medicina, https://orcid.org/0000-0002-7065-5374,Email: gilberto_palma8909@uaeh.edu.mx

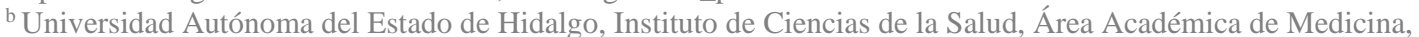
https://orcid.org/0000-0001-9966-8892, Email: dianadps103@ gmail.com

c Universidad Autónoma del Estado de Hidalgo, Instituto de Ciencias de la Salud, Área Académica de Medicina, https://orcid.org/0000-0001-9704-6942,Email: monseh.med@ gmail.com

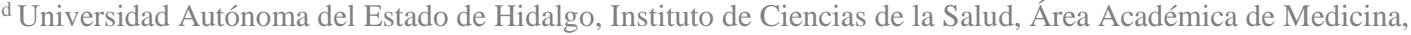
https://orcid.org/0000-0001-5135-8289, Email: rociorodriguezramirez3@gmail.com
} 
parece más probable que los grupos ancestrales fueran micoparásitos, y posterior a ellos, parásitos de plantas que se expandieron rápidamente en sustratos recientemente disponibles para las plantas terrestres.

Basidiomycota estuvo muy involucrado en la descomposición de la madera, comenzando con la podredumbre blanca y cambiando a la podredumbre marrón varias veces, y continuando descomponiendo la lignina en sucesiones específicas ${ }^{(34)}$.

A Basidiomycota pertenecen las especies más notorias en la naturaleza, por sus tamaños, colores, formas y usos que históricamente han tenido, tal es el caso de los hongos considerados alucinógenos, enteógenos, sagrados, entre otros variados nombres, motivo de este documento y que desarrollaron dependencias a diferentes sustratos de enorme importancia ecológica que los condujo, a cambios considerables; crecen en tallos, hojas, semillas, tierra, estiércol, aserrín, paja, madera muerta o entre musgos ${ }^{(38)}$.

Los hongos alucinógenos son un complejo de varios hongos diferentes como el cornezuelo de centeno (Claviceps purpurea), el hongo de las moscas (Amanita muscaria), algunas especies de los géneros Boletus y Russula así como Psilocybe.

El género Psilocybe es el grupo que se le asocia con los hongos alucinógenos utilizados desde la antigüedad en ceremonias sagradas. Está ampliamente distribuido en todo el mundo y su número escila entre 277 y 300 especies ${ }^{(16,17,26)}$.

Las sustancias psicoactivas se consideran metabolitos secundarios o especializados (alcaloides, terpenos y flavonoides entre otros). Son aquellos compuestos químicos que son capaces de cambiar el modo en que funciona la mente, como alterar las sensaciones de dolor y placer, el estado de ánimo, la consciencia, la percepción, la capacidad de pensar y de ser creativos, el estado de alerta y otras funciones psicológicas ${ }^{(20)}$

Ante esto, surgen las preguntas acerca de cuál es su función en la naturaleza, cuáles son las relaciones entre otros organismos que las producen de manera natural y los organismos que han tenido contacto con ellas de manera intencional y si fue el ser humano el que descubrió sus efectos.

Es difícil saber exactamente cuándo comenzó la relación con estas sustancias psicoactivas. Al parecer la principal función es evitar el consumo por depredadores mediante la liberación de estas sustancias, además en períodos de escasez de alimentos podría haber forzado su consumo, con el posterior descubrimiento de sus propiedades medicinales.

Los mamíferos datan del período Triásico (hace unos doscientos millones de años), por lo que es posible estimar que la interacción entre plantas, hongos y animales mediada por estas sustancias tiene quizá decenas (o hasta centenas) de millones de años de antigüedad, por lo que la presencia de sustancias psicoactivas y su uso en la naturaleza claramente precede a la aparición del hombre.

La psilocibina, es un alcaloide psicoactivo producido por al menos 300 especies de hongos distribuidos en todo el mundo. Esta sustancia forma parte del grupo de las triptaminas, un conjunto de compuestos con gran capacidad insecticida. Sin embargo, a pesar de que la psilocina tenga la capacidad de inducir estados expandidos de consciencia en seres humanos, este sistema de defensa no funciona sobre nosotros por ser prácticamente inocuo en términos toxicológicos.

La idea de que el consumo de hongos psilocibios sea fuente de inspiración para algunas formas de arte prehistórico no es nueva. Lo notable de estos trabajos etnomicológicos fue producido hace unos 7.000 - 9.000 años atrás, en donde se muestra que el uso de alucinógenos se remonta al período paleolítico y que siempre tiene lugar en contextos y rituales de naturaleza místico-religiosa.

\section{Revisión histórica}

Psilocybe mairei, especie autóctona descrita de Argelia y de Marruecos ${ }^{(19)}$. Por su forma y tamaño, bien podría coincidir con las pinturas en las cuevas de la meseta montañosa de Tassili n'Ajjer (en bereber: planicie de los ríos), en el desierto del Sahara al norte de África. Se cree que este hongo en tiempos prehistóricos crecía allá, cuando el clima no era árido ${ }^{(18)}$.

A lo largo de la historia, la región del Sahara ha sufrido grandes variaciones climáticas, desde el 20.000 a.C. ha pasado al menos tres períodos húmedos, intercalados por periodos de intensa aridez, siendo la actual aparentemente más benévola que la anterior. Hubo un período, el gran holoceno húmedo, donde existieron enormes lagos en toda la cuenca del Sahara, entre el 10.000 y 5.500 a.C., este clima permitió que se asentara la vegetación de montaña, caracterizada principalmente por poblaciones de coníferas y robles con la micobiota asociada. Abarca del paleolítico superior y del neolítico, coincidiendo con la presencia de los "Rondheads" o "Cabezas redondas", dando el máximo esplendor de manifestaciones rupestres en las zonas del Tassili, Tadrart Acacus (Libia), Ennedi (Chad) y Jebel Uweinat (Egipto) ${ }^{(36)}$.

Pinturas rupestres creadas en España hace 6.000 años sugieren que el hongo Psilocybe hispánica era consumido en el transcurso de ciertos rituales religiosos cerca de Villar del Humo municipio de la provincia de Cuenca al oeste de los pirineos en la comunidad autónoma de Castilla - La Mancha ${ }^{(4)}$. Se representan en este mural, hongos grabados en relación con una escena de caza de bisontes y venados. La identificación de Gastón Guzmán del hongo en el mural, se basa en la 
forma de las fructificaciones y por el hecho de que Psilocybe hispánica crece en estiércol, lo que la relaciona con los bisontes y venados ${ }^{(18)}$.

En el Rig Veda se nos dice que el soma es el origen del Parjanja, dios del trueno, fenómeno habitualmente ligado a relámpagos y rayos, un sobrenombre del soma ( $A j a$ Ekapad), cuya traducción es "pie único no nacido", los mayas Quiché de Guatemala hablan del hongo Kakuljá Huracán, como un "rayo de una pierna", epíteto que recuerda al Aja Ekapad hindú (14).

Cabe acotar que el hongo que se relaciona con la bebida sagrada el "Soma" en la religión védica y el "Ahoma" del zoroastrismo iranio, al parecer equivalentes, es la Amanita muscaria que por cierto era principalmente consumido en la península de Yucatán. La Amanita muscaria o agárico de la mosca no tiene psilocibina, pero si muscimol y ácido iboténico que generan además de delirios, espasmos musculares y malestares gastrointestinales, alucinaciones de tipo liliputienses en el que se ve a las personas reducidas de tamaño, o más grande de lo normal llamadas alucinaciones gulliverianas. Es probable que el uso de Amanita muscaria fuera abandonado al descubrir los mayas las propiedades de los hongos neurotrópicos del género Psilocybe, que no producen ningún trastorno gástrico y que son más abundantes ${ }^{(18)}$

En el códice Madrid (códice Tro - Cortesiano), uno de los pocos códices mayas que se salvaron de la destrucción en 1562 que de ellos hizo Fray Diego de Landa por considerarlos heréticos, hay representaciones de hongos que han sido interpretadas como Amanita muscaria, lo que permite suponer que esta especie fue utilizada en cierta época por los mayas, con fines rituales, relacionando a este hongo con la leyenda del trueno, que aún persiste en algunos lugares de Guatemala y Chiapas (22)

En la actualidad los Sandales de la India consumen un hongo como sustituto del desaparecido soma, lo llaman "putika" y de él dicen que es un hongo provisto de vida, se piensa que es el Psilocybe cubensis, una especie coprófila abundante en las montañas de Nepal ${ }^{(14)}$.

En Japón la obra Konjaku Monogatari "Cuentos de Antaño" escrita en el siglo XI incluye un cuento sobre monjas y leñadores que se embriagaban en el bosque después de ingerir maitake u "hongos danzantes". Hoy día se identifica el maitake con la especie Grifola frondosa que no contiene psilocibina. Dentro de las varias especies japonesas psilocíbicas están el o-waraitake "gran hongo de la risa" (Gymnopilus spectabilis). El warai-take "hongo de la risa" (Panaeolus campanultus), una de las primeras especies de teonanácatl identificadas en México. Varias fuentes chinas describen los efectos del Hsiao-chun "hongo de la risa"; y el shibire-take "hongo que entorpece" (Psilocybe venenata).

Existe un poema japonés senryu acerca del warai-take:
"Sería bonito hacer que el kunikaro comiera warai-take!" que expresa el deseo de que el severo kunikaro, el capataz del señor feudal, ingiriera "el hongo de la risa" y se "alegrara" un poquito ${ }^{(35)}$.

Psilocybe semilanceata de amplia distribución en Europa, sobre este hongo, existe el primer caso de una intoxicación neurotrópica que involucró al padre y sus cuatro hijos, registrado en Inglaterra en 1799, la identificación de la especie fue gracias al libro de 1803 de James Sowerby "Coloured Figures of English Fungi or Mushrooms". Roger Heim estudió en 1971 dicho caso e identificó los hongos registrados por Sowerby, los cuales fueron una mezcla de Stropharia y Psilocybe semilanceata $^{(18)}$.

En Papúa Nueva Guinea, en el Valle de Wahgi, área en la que entraron por primera vez los forasteros en la década de 1930, vive un pueblo ágrafo llamado Kuma. El primer documento escrito acerca de los Kuma hace referencia al hecho de que ingerían un hongo silvestre llamado "nonda" que vuelve al que lo consume temporalmente loco. Roger Heim y Robert Gordon Wasson pasaron tres semanas recolectando especímenes en el valle de Wahgi en 1963 junto con la antropóloga Marie Reay, encontraron once especies de hongos responsables del komugl tai "locura de los hongos" que afecta sólo a los hombres, o del ndaadl "delirio de los hongos" que afecta sólo a las mujeres. Heim y Wasson concluyeron que la "locura de los hongos" de los Kuma era un fenómeno extrafarmacológico.

Aunque los Kuma atribuyen las manifestaciones de locura a los hongos, creen que "aquellos destinados a sucumbir, sucumbirán coman los hongos o no". No obstante, Heim informó de la presencia de trazas de tres compuestos indólicos no identificados en Boletus manicus, y en autoexperimentos realizados con este hongo pulverizado (con una cantidad de polvo inferior a los $60 \mathrm{mg}$ ), Heim en 1965 afirmó que la "ingestión provocaba la aparición de visiones luminosas muy coloridas". Más tarde Heim y Wasson recolectaron un hongo en 1967 que se tornaba azulado y lo describieron como enteogénico, lo nombraron Psilocybe kumaenorum. Los nativos lo llaman "koull tourroum" o "koobl tourrum". Este hongo es indudablemente psilocíbico y es cercano a la conocida especie Psilocybe zapotecorum ${ }^{(35)}$.

En Nueva Zelanda se ha descrito recientemente el uso de Psilocybe kumaenorum con fines lúdicos, junto con la especie relacionada Psilocybe novaezelandiae y es posible que se use del mismo modo en Australia. Sin embargo, Gastón Guzmán en 1991 dijo del Psilocybe novaezelandiae que "no se tornaba azul" y lo situó en la sección Pratensae, donde no se encuentran especies psilocíbicas conocidas. El estatus de esta especie como hongo enteógeno es por tanto dudoso, a pesar del escrito sobre su uso lúdico en Nueva Zelanda ${ }^{(35)}$.

Horak en 1978 describe que en África central el pueblo Banza consume Pluteus atricapillus variedad ealensis, de olor acre y sabor amargo. El hongo es conocido entre los 
Eala del Zaire con el nombre de "losulu" y con el de "abanda" entre los Banza. No se daban más detalles, el Pluteus atricapillus contiene psilocibina / psilocina ${ }^{(35)}$.

En el Amazonas peruano, los misioneros jesuitas el siglo $\mathrm{XVII}$, describieron el uso entre los indios Yurimagua de una poción enteogénica preparada a base de "hongos que crecen en los árboles caídos". Puede que se tratara del lignícola Psilocybe yungensis, que se encuentra habitualmente en Colombia, Ecuador y Bolivia en Sudamérica, pero que nunca ha sido recolectado en Perú. Otra posibilidad sería la especie Dictyonema, un "hongo arborícola" que se dice que fue usado por los chamanes ancestrales Waorani como embriagante enteogénico en el Ecuador Amazónico, con el nombre de nenendape. Como tercer candidato, Gartz en 1993 propuso recientemente al hongo psilocíbico lignícola Gymnopilus purpuratus de Sudamérica ${ }^{(35)}$.

Se ha descrito el uso de Psilocybe yungensis por los indigenas Mazatecas y Mixe, e indudablemente contiene psilocibina / psilocina. Wasson calificó esta especie de enteogénica, después de ingerirla en julio de 1958 en Rio Santiago, Oaxaca ${ }^{(35)}$.

Fue Carl Sapper quien en 1898 identificó por primera vez los arqueológicos hongos de piedra de las zonas altas de Guatemala y en su vertiente del pacifico, en el sur de México y el Salvador, rechazando sobre obvias bases morfológicas, la noción de que habían servido como símbolos fálicos en algún culto de la fertilidad. La asociación hongo - jaguar es especialmente interesante a la luz de la mención, en el diccionario de Coto, de un hongo llamado "oreja de jaguar" (13). Las «piedras fúngicas» miden entre 20 y $40 \mathrm{~cm}$, las más antiguas están fechadas entre el 1000 y el 1200 a.C. en el preclásico y el clásico ${ }^{(1)}$, las más recientes al 800 y 900 d.C. ${ }^{(23)}$.

Desafortunadamente no han sido halladas en contexto arqueológico salvo contadas excepciones, caso de una tumba en Kaminaljuyú y Chimaltenango en Guatemala donde encontraron nueve miniaturas acompañadas de metates (morteros) con sus correspondientes "manos" y de una antigüedad aproximada de unos 2200 años, S. de Borhegyi plantea de estar relacionados con los nueve señores de Xibalba, tal y como fueron descritos en el Popol Vuh, libro sagrado de la mitología maya-quiche ${ }^{(13)}$. El Popol Vuh habla de holom ocox, "cabeza de hongo", y en los Anales de los cakchiqueles que se refieren a hongos (que crecen al pie de los árboles). Ambas obras expresan que estos hongos eran usados por los "naguales", lo que hoy día entenderíamos por chamanes, aunque en realidad no son lo mismo. M. de la Garza refiere a la Amanita muscaria que crece en las tierras altas mayas, era conocido entre los nahuas, los aztecas como tzontecomananacatl, "hongo de cabeza". La Amanita muscaria se aproxima más a la fisonomía de las estatuillas mayas que a los hongos psilocíbicos ${ }^{(2)}$.

Tanto en el área cercana a la provincia panameña de Darien, como en la región colombiana de Quimbaya, se han localizado varios pectorales de oro en los que se pueden observar cuerpos semiesféricos sobre las cabezas de algunas figuras representadas, este "Pectoral de Darien" data del 1000 - 1500 d.C., pertenecientes a la cultura Mochica y se cree que pudieran tratarse de hongos alucinógenos, Psilocybe o bien Panaeolus sphinctrinus. Algunos de estos pectorales fueron localizados en un cenote en Chichen Itzá, en la península de Yucatán, lo que supone una difusión de prácticas mágico - religiosas ${ }^{(2)}$.

\section{México}

Existen entre 277 y 300 especies de hongos del género Psilocybe y al menos 54 se encuentran en México, sobre todo en la costa atlántica ${ }^{(6)}$. Estas especies están agrupadas en 14 géneros que crecen por todo el mundo y la lista aumenta cada año, por lo que se puede afirmar que la psilocibina es la toxina fúngica más ampliamente distribuida ${ }^{(45)}$. El mayor número de especies del género Psilocybe en el territorio mexicano se encuentran en los bosques subtropicales, conocidos también como mesófilos de montaña ${ }^{(15)}$.

El culto a los hongos sagrados se extendió desde el valle de México a toda América central, y su antigüedad se estima en al menos 3.500 años. Los mayas consumían "K'aizalaj Okox" Psilocybe cubensis y los aztecas los llamaron Teonanácatl ${ }^{(6)}$.

Al noreste de México en Colima, Jalisco y Nayarit. Hay unas efigies funerarias que tienen dos "cuernos" que sobresalen de la cabeza y los arqueólogos creen que representan sacerdotes o "deidades" masculinas y femeninas relacionadas con los hongos (del año 100 a.C. al 300 - 400 d.C.) Asimismo, las tradiciones de los indígenas huicholes de Jalisco indican la posibilidad de que estos hongos se hayan empleado religiosamente desde tiempos muy remotos ${ }^{(44)}$.

Merle Greene Robertson especialista en arte maya clásico, en 1972 escribe acerca de los monumentos tallados de Yaxchilán, zona lacandona en el rio Usumacinta. Se entera que sacerdotes lacandones consumían los hongos en forma ritual, algunas veces dentro de las ruinas del templo o en las estructuras funerarias de Yaxchilán. Los hongos se preparan dice, en tazones de barro especialmente consagrados para ese propósito y que difieren de las llamadas "vasijas de los dioses", que tienen decoraciones antropomórficas en las que se quema el incienso. Robertson supo a través de informantes que los hongos sagrados han servido como medio de comunicación con los dioses "hasta donde el más viejo" de este grupo en particular logró recordar ${ }^{(13)}$.

Cuentan los abuelos lacandones que:

"Hachäk'yum, el dios creador de las montañas de los ríos, de las aves, de los peces y todo lo que hay en la selva, después de haber creado a los hachwinik a los hombres verdaderos, se sentó a descansar un momento en un tronco. Como tenía hambre, comió unos brotes de una planta. Cuentan que aquellas migajas que se caían de su 
boca sobre los troncos dieron origen a los kuxum che' (hongos de los palos), en tanto que aquellas migajas que cayeron sobre la tierra dieron origen a los kuxum lu'um (hongos de la tierra). Los hombres verdaderos contemplaban extasiados cómo el padre creador se deleitaba con tan suculentos manjares y, como era natural, se acercaron a pedirle a Hachäk'yum que les compartiera de eso que se veía tan delicioso. Sin embargo, su padre les dijo que esos hongos no podían comerlos nunca porque eran comida de los dioses. Pero tal era su amor por sus hijos que les purificó algunos hongos para que también se deleitaran" (24).

El tratado del misionero dominico Domingo de Vico (1485, 1519 - 1555) De acuerdo a la Real Academia de la Historia nace en la ciudad de Úbeda, Reino de Jaén, Verapaz (Guatemala) sitúan su nacimiento con dos fechas $(1485,1519)$. Realiza una de las más viejas listas coloniales de palabras conocido como el diccionario de Vico (compilado antes de 1550) "Vocabulario de la lengua cakchiquel con advertencia de los vocablos de las lenguas quiche y tzutuhil". Explícitamente menciona un hongo llamado xibalbaj okox (xibalba, del submundo, o infierno, morada de los muertos; okox, hongo). En este contexto no solo remite al inframundo maya con los nueve señores y nueve niveles, sino que significa "tener visiones".

Este mismo hongo es mencionado en la obra de fray Tomás de Coto "Vocabulario de la lengua cakchiquel o guatemalteca" (compilado antes de 1690). Aquí xibalbaj okox (hongo del submundo) se denomina también káizalah okox que puede traducirse como "hongo que hace que uno pierda el juicio" y a kek qim ti qhuhirican hongos "que embriagan" (35).

Kakuljá icox "hongo del rayo", muestra una relación entre los hongos y los rayos, con vínculos religiosos, lógicamente debido a que los hongos nacen en la temporada de lluvia, este hongo también es conocido por Itzel ocox, "hongo malo", y podría tratarse de Amanita muscaria ya que en las tierras altas de Chiapas se la conoce como Yuy Chauk, es decir "Yuyo del rayo".

Coto también describe un hongo el llamado $k^{\prime} e$ kc'un, "que embriaga o emborracha" y el otro muxan okox, "hongo que enloquece a quien lo come" (de mox, que significa "hongo" en las lenguas zoque-mixe del sur de México, y "loco" o "que cae en un desmayo en el mayacakchiquel del altiplano guatemalteco). De acuerdo a los lingüistas Lyle Campbell y Terrence Kaufmann, creen que muxa $n$ okox es uno de los varios casos de préstamo lingüístico de términos rituales de los zoque - mixe a las lenguas mayas de los viejos tiempos, quizá desde el año 1000 a.C. o incluso antes. Puesto que ellos también postulan el zoque - mixe como el idioma de los olmecas (la cultura "madre") es tentador sugerir que los olmecas pudieron ser el instrumento de la expansión de cultos fungómanos ${ }^{(13)}$.

Se ha descrito su uso de Psilocybe cordispora, por los Mixe y Mazatecas de Oaxaca, México. Los Mixe llaman a este hongo "Atkat" y la dosis típica que utilizan en la adivinación chamánica es de 12 o 13 pares de hongos ${ }^{(35)}$.

En el tratado de Tomas de Coto se recoge que:

“.... Es menester conocerlos para comerlos, porque ai unos que son malignos y mortíferos $y$, por lo menos a los que los comen, hacen perder el juicio. A éstos llaman: kaizalah ocox o xibalbay ocox. Otros que embriagan: kek qim ti qhuhirican" (2).

La obra de fray Toribio de Benavente (1482-1569) más conocido por Motolinia, nombre que el mismo adopto para así ser nombrado, el cual significa pobre o afligido en náhuatl y que procede de mo (es/se) y tolinia (pobre/afligir), es decir el que es pobre o se aflige. Autor de la obra "Historia de los indios de la Nueva España", en ella nos deja una de las mejores descripciones de los efectos y del carácter ritual y sagrado de estos hongos:

"Tenian otra manera de embriagarse que los hacia más crueles, y era unos hongos o setas pequeñas, que en la tierra las hay como en Castilla; más los de estas tierras son de tal calidad que, comidos crudos y por ser amargos, beben tras ellos o comen con ellos un poco de miel de abejas; $y$ de allí a poco rato veían mil visiones, en especial culebras, y como salían fuera de todo sentido, parecíales que las piernas y el cuerpo tenían lleno de gusanos que los comían vivos, y así medio rabiando se salían fuera de casa, deseando que alguno los matase; y con esta bestial embriaguez y trabajo sentían, acontecía alguna vez ahorcarse, y también eran contra los otros, más crueles. A estos hongos llaman en su lengua teunanacatlth, que quiere decir carne de dios, o del demonio que ellos adoraban; y de la dicha manera con aquel y amargo manjar su cruel dios los comulgaba" $(33,2)$.

El franciscano Bernardino de Sahagún (1499 - 1590) El título original de su obra era" Historia Universal de las Cosas de Nueva España" pero tras un error de traducción paso a ser la "Historia General de las cosas de la Nueva España". Se conoce como Codex Florentinus o Códice Florentino y anteriormente Códice Laurentino, Ilamado así porque se conserva en la Biblioteca Medicea Laurenciana de Florencia. Se trata de una copia que envió Sahagún a Roma con el padre Jacobo de Testera para que fuera entregada al papa Pio V en $1580{ }^{(7)}$.

En su obra curiosamente el fraile denomina setas a las especies comestibles, mientras que cuando menciona la palabra hongos lo suele hacer más bien para referirse a su carácter intoxicante, que no venenoso ${ }^{(2)}$

De los comestibles describe como tzontecomananácatl, que dice que son grandes y redondos; xelhuaznanácatl, bajos y con pies y crecen muchos; chimalnanácatl, anchos y redondos; menanácatl, blancos y redondos; zacananácatl, redondos, altos y con pie delgado; y quauhnanácatl, que se caracterizan por crecer en los árboles". En el párrafo quinto del libro XI del Florentino se describen a las hierbas medicinales y es posible observar una representación de un hongo, así como una breve 
mención en náhuatl: "Nanacatl, teonanacatl, atona uizpatli [atonahuizpatli]", que alude a su potencial para curar la fiebre, lo que explicaría la presencia de un personaje fantástico representado arriba del sombrero del hongo que podría estar haciendo referencia a la alucinación provocada por la fiebre, y que se esperaría ser sosegada al consumir este hongo ${ }^{(24)}$.

«Hay unos honguillos en esta tierra que se llaman teonanacatl. Críanse debaxo del heno en los campos o páramos. Son redondos, y tienen el pie altillo y delgado y redondo. Comidos son de mal sabor; es amargo y quema; dañan a la garganta y emborracha. Son medicinales contra las calenturas y la gota. Hanse de comer dos o tres, no más. Lo entristece a uno, lo deprime, lo hace reír, lo asusta, lo hace esconderse. Los que los comen ven visiones y sienten vascas del corazón, y ven visiones a las vezes espantables y a las vezes de risa. Se acongoja, se cuelga, se precipita de un acantilado, llora, se asusta. Se comen con miel. A los que comen muchos de ellos provocan a luxuria, y aunque sean pocos. Como hongos; tomo hongos, de uno que es altanero, presuntuoso, vano, de él se dice: "Este se embriaga con hongos solo". Y a los mozos locos y traviesos dízenles que han comido nanácatl» $(6,46,2,1)$.

Su funcionalidad viene perfectamente descrita en un breve pasaje donde se comenta la celebración de una "fiesta" por unos mercaderes:

"El día señalado los participantes del ágape tomaban los "honguillos negros" o nanacatl mezclados con cacao (Theobroma cacao L.) y miel; poco después del ritual algunos comenzaban a bailar y otros a llorar, asaltados por distintas visiones, mientras que había quien se sentaba pensativo o simplemente soñaba. Al concluir el efecto hablaban entre si contando sus visiones a fin de poder entenderlas mejor" (2).

El médico Francisco Hernández (1514-1578), enviado por Felipe II a estudiar la medicina azteca, también se ocupó del tema. Su expedición, una de las más ambiciosas realizadas hasta el momento con fondos gubernamentales, culminaría con la redacción de la obra titulada "Historia Natural de la Nueva España" (2).

"Otros cuando se comen, no causan muerte sino locura, que en muchas ocasiones es permanente; su síntoma es una especie de risa incontrolable. Por lo regular se les llama" teyhuintli", son de un color amarillo subido, picantes y de una frescura no desagradable. Existen otros que, sin inducir risa, producen visiones de todo tipo, como guerras o imágenes de demonios. Hay otros que son muy apreciados los príncipes en sus fiestas y banquetes. Se procuran en vigilias importantes y terribles que duran toda la noche. Este tipo es de color tostado y algo picante en su sabor" (44).

Teunamacatlth o teonanácatl era el nombre que recibían los hongos en Náhuatl, la palabra se podría traducir con mayor precisión por la expresión "hongo maravilloso" u "hongo sagrado", también era conocido de forma más prosaica por el nombre teyhuinti-nanácatl, "hongo embriagante" (35).

Los que menciona Bernardino de Sahagún y algunos de los descritos por Francisco Hernández se cree que pudieran ser de la especie Psilocybe mexicana que crece en el musgo de los bosques de pinos y encinas. Además, parecen existir al menos dos clases diferentes: unos para "fiestas" y otros para "adivinaciones". Los hongos estaban destinados a producir trances extáticos y adivinatorios. ${ }^{(2)}$

En los códices mayas Dresde y Madrid, hacen referencia de que los hongos fueron empleados en las ceremonias de coronación de diversos emperadores aztecas, entre ellos Tizoc, Ahuízotl y Motecuhzoma Xocoyotzin ${ }^{(6)}$.

El códice Vindobonensis (Codex Yuta Tnoho), fue llevado a Europa durante o después de la invasión (1519 - 1521) y presentado al emperador Carlos $\mathrm{V}$, quizá junto con el códice Nuttal. Posee información de los señoríos de la Mixteca Alta y se plasma numerosos mitos relacionados con la cosmología mixteca entre ellos el mito de la creación ${ }^{(29)}$. En los folios 24 y 25 se encuentra la historia relacionada de la primera aparición del sol y su relación con hongos considerados un elemento sagrado, he aquí un fragmento:

"La historia comienza a orillas del río Apoala o Yuta Tnoho, con la reunión de dos ñuhu (nombre que los mixtecas usan para los seres sagrados incluso hoy), 9viento o Coo Dzavui, quien representa a Quetzalcóatl, la serpiente emplumada de los mexicas. Luego aparece 4Lagarto transformado en los hongos sagrados para ser consumidos, después de lo cual 9-viento se muestra muy bien vestido y cargando su espalda, 4-Lagarto, con tres hongos transparentes en su cabeza. Estas deidades van a un lugar donde está el precursor del maíz, Tláloc y el valle de los antiguos muertos. Debajo está una de las escenas más bellas de la historia, donde 9-viento canta acompañado de música producida al raspar un hueso contra un cráneo humano. Frente a él, con lágrimas en los ojos y sosteniendo en la mano dos hongos, está 7viento o Pilzintecuhtli, el príncipe de las flores representado por Xochipilli entre los mexicas. Las lágrimas son probablemente el resultado del trance. En el fondo se muestran a los dos ñuhu que comenzaron la historia acompañados en esta ocasión por un insecto nocturno que sugiere que la ceremonia del hongo se llevó a cabo por la noche, tal como se realiza actualmente en los grupos éticos mexicanos" (21).

El códice Vindobonensis, indica de acuerdo con Alfonso Caso, la importancia de los hongos en determinadas festividades religiosas ${ }^{(22)}$.

En el códice Magliabechiano (1530), creado en el periodo colonial temprano, forma parte de un conjunto de códices que incluyen el Códice Tudela y el Códice Ixtlilxóchitl. Se llamó así en honor a Antonio Magliabecchi, un archivero, coleccionista y bibliógrafo italiano del siglo XVII quien lo 
rescató, ignorándose el cómo fue a parar a sus manos ${ }^{(8)}$. En él se describe la ingestión del teonanacatl., "se les hizo ver a los indios que el comer esos "hongos del demonio" estaba prohibido y que por ello dibujaran el diablo al lado de los hongos". Pero al no conocer los indios el diablo, dibujaron atrás de quien consumía el hongo verde a un personaje "maligno" que bien podría ser el "dios" del hongo o Mictlantecuhtli el señor del Mictlán, no se sabe. Gastón Guzmán identificó el hongo verde del Códice Magliabechiano con Psilocybe zapotecorum, especie sagrada común en México ${ }^{(18)}$.

El fraile dominico Diego Durán (1537 - 1588) autor de la obra "Historia de las Indias de Nueva España i Islas de Tierra Firme", en donde se concreta a la historia de los mexicas (tenochcas), desde su salida de Aztlán hasta la muerte de Cuauhtémoc, en ella describe gracias a sus fuentes la coronación del emperador azteca Ahuitzotl alrededor del año 1486:

“... jamás hace memoria de que bebiesen vino de ningún género para embriagarse, sino sólo los hongos monteses, que los comían crudos, con los cuales... se alegraban y regocijaban y salían algo de su sentido, y del vino nunca hace memoria... sólo hace memoria de la abundancia de cacao que se bebía en estas solemnidades".

Henry Munn ha subrayado la relación entre el cacao y los hongos enteógenos en el chamanismo mazateca contemporáneo ${ }^{(35)}$.

En la conmemoración de la entronación de Motecuhzoma Xocoyotzin refiere que, para dar un aspecto solemne al acto, se comían algunos hongos que, lógicamente les hacían perder el sentido. De su efecto escribió que producían un estado de embriaguez como si quien lo ingiriese hubiese bebido una gran cantidad de vino. Les producían una serie de visiones con las que aparentemente se les revelaba el futuro ya que, bajo los efectos del hongo, creían que el demonio venia y les contaba su destino. Esta fiesta era conocida como la de las revelaciones ${ }^{(2)}$.

Colectando Gastón Guzmán hongos en 1959, en una barranca de la Sierra de Puebla, ubicada en la zona náhuatl entre Necaxa y Chignahuapan, observó muchos altares cristianos en la pared rocosa. Al preguntarle a unos indígenas sobre el nombre de los hongos que había colectado (eran especímenes de Psilocybe caerulescens, $P$. cubensis y $P$. zapotecorum), ellos se sorprendieron, por el hecho de que un blanco tenía en sus manos hongos sagrados. En aquella época, era inusual que los blancos conocieran tales hongos, porque además de que eran sagrados, eran un secreto. Después de que Guzmán insistió en el nombre de tales hongos, le dijeron que se llamaban teotlaquilnanácatl. (Obsérvese que esta palabra es muy semejante a la de teonanácatl de Sahagún, únicamente con el prefijo tlaquil intercalado). Dicho prefijo significa pintura o pintar, por lo que la denominación teotlaquilnanácatl significa, "el hongo sagrado que pinta", lo que es bastante significativo acorde con las propiedades neurotrópicas de estos hongos. Guzmán en
1960 hizo ver que la denominación correcta es Teotlacuilnanácatl, debido a que tlacuil significa pintor, precisamente fueron los tlacuilos los que dibujaron los códices ${ }^{(18)}$.

Los frailes asumieron que la palabra Theo "dios en griego" y Teotl "eran lo mismo», sin embargo, para los Anahuacas no existía ni existe como tal la palabra "dios", ya que basan sus conocimientos en acontecimientos cósmicos. No había religiones, sino una forma de vivir llamada Toltecayotl ${ }^{(31)}$. Si Teotl es energía, esencia o fuerza, nacatl, carne o cuerpo, entonces Teonanácatl se traduciría en hongo o cuerpo de energía, esencia o fuerza. Luego entonces Teotlacuilnanácatl sería: hongo que pinta o describe a través de visiones "vislumbra" energía, esencia o fuerza ${ }^{(2)}$.

A mediados del siglo XIX se localizó en Tlalmanalco, a los pies del volcán Popocatépetl, una escultura conocida como Xochipilli, "el príncipe de las flores", muestra dentro de los elementos principales un par de hongos en sus manos, además de un emblema que rodea el pedestal donde se asienta la estatua. El motivo de carácter vegetal - cinco figuras convexas con sus extremos vueltos hacia el interior y dispuestas en círculo, al que se añade un sexto cubierto por una mariposa que podría corresponderse con hongos representados de manera transversal. Para Gastón Guzmán la especie sería concretamente Psilocybe aztecorum cuyo hábitat se limita a esa región.

La mariposa parece jugar un papel importante ya que dentro de su mitología se encuentran relacionadas con el país de los muertos y simbolizan los espíritus de las personas fallecidas. Por dicho motivo Robert Gordon Wasson interpreta que la mariposa en el pedestal parece indicar que el hongo, del cual cree que pudo haber sido el alimento de los dioses, podría transportar, por un breve periodo de tiempo, a los vivos a ese otro mundo donde los problemas cotidianos no existirían. El resto de los hongos esculpidos permanecen sin identificar ${ }^{(6,2)}$.

Aunque los hongos no florecen, los aztecas los llaman "flores", y los indígenas que aun los utilizan en sus rituales los Ilaman "florecitas" (44). Un dato interesante recogido en el diccionario de la lengua náhuatl de Rémi Simeón (1885) es la referencia al xochinanacatl, "hongo pequeño que embriaga". Sin embargo, este término significa literalmente "hongo flor" por lo que M. de la Garza plantea que podría estar relacionado con un poema de los Cantos principescos de Tecayehuatzin Huexotzinco (poeta gobernante de la región poblano - tlaxcalteca), que habla de las flores de Tamoachan, entre las cuales hay una "sin raíces". En la poesía náhuatl las flores son un elemento de carácter simbólico que pueden representar diversas cosas: el pensamiento, la palabra, la guerra, la muerte etc...También puede aludir a plantas psicotrópicas y parece posible que a los hongos. De hecho, en varios poemas aparecen referencias a hongos y sus cualidades visionarias o embriagantes ${ }^{(2)}$. 
Según los textos aztecas, el Tlalocan estuvo cerca de Tlalmanalaco, donde se encontró la escultura de Xochipilli, príncipe y señor de las flores psicodélicas. Pilzintli, Pilzintecuhtli o Teopiltzin, todas son una especie de manifestación de Xochipilli, sus nombres significan dentro del sincretismo, "niño dios" y es el patrón de la "gentecita" o "niños santos", ambos nombres cariñosos para los hongos ${ }^{(1)}$.

Los Frescos de Tepantitla en Teotihuacán, en el alto valle de México, datado en el 500 d.C, muestra el culto a Tláloc, señor del rayo y de las aguas, que, bajo sus gotas, surgen figuras sacerdotales con hongos alucinógenos ${ }^{(6)}$. En él se observa el árbol sagrado de Tamoachan, situado en el lugar mítico y a su vez relacionado con el árbol sagrado del Tlalocan, el árbol de la vida ${ }^{(5)}$. El Tlalocan era el cielo de los ahogados, los reumáticos, los leprosos y de los fulminados por el rayo. En esta proximidad pictórica con el agua, a los hongos sagrados se los relaciona con el señor de las lluvias al ser llamados apipiltzin "pequeños hijos de las aguas" (23). El encargado de los nanacatl era Nanacatzin (nacatl, carne y tzin partícula reverencial en lengua náhuatl), el hacía que por la noche salieran los hongos de la tierra húmeda ${ }^{(5)}$. El hongo es por tanto una de las manifestaciones del poder de Tláloc.

En el Códice Borbónico de (1562-1563) se observan símbolos fungoides en relación con Tláloc señor del agua y de la lluvia, quien propicia el desarrollo de hongos, así como una relación de hechiceros, lo cual sugiere el uso de alucinógenos en ceremonias religiosas o en ritos mágicos (22). Estos hongos plasmados en el códice al parecer hacen referencia a una especie de pradera, higrófila, incluso acuática, propia de los pantanos y de aquellos lugares donde predominaba una intensa humedad, creciendo en las fronteras entre las tierras cálidas y las frías, hacía unos $900-1.800 \mathrm{~m}$. de altitud en zonas intensamente húmedas: Psilocybe zapotecorum (23).

En una entrevista a profesora Guadalupe Villareal oriunda de la localidad de San Miguel Coatlinchán, refiere que, en el Museo Nacional de Antropología e Historia, esta ella y no él. Está Chalchiuhtlicue y no Tláloc. Es la piedra de los Tecomanes, sacada de su sitio el 16 de abril de 1964. Tláloc es el señor de las aguas celestes, de la lluvia y Chalchiuhtlicue era la señora de las aguas terrestres. El está arriba y ella está abajo, pero no están separados, porque los une la serpiente de agua. Villareal recuerda que cuando ella era niña y visitaba la piedra, alrededor se oían risas, como duendes., y agrega: Tláloc está aquí en la montaña a 4 mil 175 metros. Es el centro ceremonial más alto del mundo. Ni Machu Picchu ${ }^{(10)}$.

En un informe titulado "Una Relación sobre los Hongos Alucinantes" elaborado en 1970 por Luis Reyes G., refiere lo siguiente:

El texto que aquí se presenta me fue proporcionado por una mujer de 70 años de edad aproximadamente, hija de una partera empírica cuya actividad se desarrolló en
Amatlán de los Reyes, Veracruz, hasta la primera década de este siglo. Para las generaciones viejas del lugar, la tierra es un ser viviente que "nos está viendo", "nos está oyendo". La Tierra como madre de todo ser viviente es también la que otorga el conocimiento de la medicina a los humanos, conocimiento que se revela en sueños o por "muerte y vuelta a la vida" del individuo. Pero aparte de la revelación que por sí misma hace la tierra a ciertos sujetos, cualquier individuo puede provocar un estado de éxtasis ingiriendo hongos narcóticos para consultar a los habitantes del Tlalocan lo que desean saber, incluyendo esto, lo que pudiera llamarse consulta médica. Estos habitantes del Tlalocan que acuden al auxilio del narcotizado son los niños muertos sin bautismo que han pasado a ser xokoyomeh (rayos), de color azul que viven con el Padre y Madre de este sitio mítico cuya entrada son las cuevas.

Reyes añade que la siguiente narración fue obtenida en lengua náhuatl y que para su traducción procuró conservar las formas sintácticas propias de la informante:

"Los antiguos padres y madres acostumbraban, cuando algo perdían, o si pues querían saber algo, ya sea donde andan sus maridos, ya sea quien los embrujó, o ya sea si quieren saber si sanarán, si llevará tiempo su enfermedad: tomaban hongos que llamaban tlakatsintsin (hombrecitos), y ellos les contestaban, les decían lo que querían saber. Y cuando los van a tomar se necesita (sea) cuando nadie haga ruido; los perros los van a amarrar lejos, el gallo que saben que va a gritar lo van a hospedar lejos, nadie hará ruido, nadie gritará. Quien los toma, primero reza un credo, ruega que le contesten (los hongos), sahúma los hongos. Luego se acuesta, uno por uno se los va comiendo. Dicen que comían veinte y los de cabeza fuerte treinta comían. Si alguien de mal carácter, si alguien sin respeto los toma, no le contestan nada, va sin rumbo, siente que le echan encima culebras. $Y$ la que bien y sinceramente los toma empieza a ver muchos hombrecitos como niños, con ellos empieza a platicar y estos hombrecitos le dicen todas las cosas a causa de que allá del Tlalocan vienen; es pues la tierra la que contesta porque sobre ella estamos, por eso todas las cosas ella sabe, la tierra nos está viendo y ella contesta" (39).

Fuentes históricas testifican que estas plantas sagradas eran utilizadas ritualmente por especialistas en la materia; ingeridas por el consultante con fines adivinatorios, a raíz de una enfermedad larga e incurable, para saber su origen y encontrar una cura; para saber el paradero de personas, objetos y animales extraviados o hurtados ${ }^{(23)}$.

En la cuenca de México, el valle de Toluca era conocido como Matlatzinco y estaba habitado por matlatzincas y ocuiltecas que convivían con mazahuas, hñahñu (otomíes) y nahuas. En La actualidad, el culto a los hongos sagrados de los matlatzincas (Psilocybe wassonni o muliercula) se puede encontrar únicamente en dos poblaciones indígenas. San Francisco Oxtotilpan (matlatzinca) y San Pedro Tlanixco (con población 
náhuatl), este último localizado en la cercanía de Tenango de Arista.

Ambos pueblos están asentados en los valles y barrancas que circundan el nevado de Toluca. Es importante destacar que además de las repetidas alusiones de los cronistas al estado de embriaguez, intoxicación o percepción alterada de la realidad, refieren que, como parte de las visiones inducidas por los agentes psicoactivos de los hongos Psilocybe, era posible que los participantes en la velada adivinaran el futuro y revelaran lo desconocido, incluso a aquellos que no los habían ingerido.

En Teotenango a la persona que tiene conocimiento de los hongos se le llama "trabajador del cielo". Entre los graniceros de los pueblos cercanos del volcán Popocatépetl a los hongos se les conoce como apipiltzin, "niños de agua", "los que nacen solos"; los matlatzincas de San Francisco Oxtotilpan los Ilaman netochutata "pequeños señores sagrados, hombrecitos y mujercitas" (Psilocybe wassonni), y los mexicanos de San Pedro Tlanixco utilizan su equivalente en náhuatl: cihuatzitzintli, "señoritas" o "niñas".

La característica relevante para ingerir los hongos sagrados, después de sahumarlos con humo de copal con gran reverencia en el altar, se muelen sobre un metate con agua limpia o agua de lluvia recolectada en oquedades de las rocas que no han estado en contacto con la tierra. Estas formas de preparar los hongos, frescos y molidos o secos y pulverizados, además del hecho de masticarlos, parecen haber sido las predilectas durante la antigüedad. La utilización en contextos rituales de las tres especies de Psilocybe (wassonni, mexicana y aztecorum) que hay en el Altiplano Central, estado de México, Oaxaca y Veracruz, se ha conservado hasta hoy.

Durante las excavaciones arqueológicas en Teotenango se recuperaron varias maquetas de andesita basáltica local, bosquejadas en templos, labradas sobre las peñas de los afloramientos naturales y se decoraron con petroglifos de escalinatas, diseños lineales y cavidades que tenían la función de recoger agua de lluvia. A manera de hipótesis se puede decir que el amplio complejo de petroglifos que se encuentra ampliamente distribuido por toda la zona arqueológica estaba estrechamente relacionado con la costumbre en la antigüedad de moler hongos con agua virgen sobre los modelos de los templos y las rocas con petroglifos.

Debe mencionarse en especial una escultura de una colección particular de Nueva York, en la cual la efigie esculpida sobre el tallo del hongo representa una mujer moliendo sobre un metate (1). En Kaminaljuyú, Guatemala, se encontraron nueve piedras fúngicas cuyos tallos muestran figuras antropomorfas con la costumbre de moler en polvo los hongos sagrados ${ }^{(6)}$. Robert Gordon Wasson en una visita al pueblo mazateca de Juxtlahuaca, en 1960, vio el consumo del hongo en forma líquida. Allí una joven machacaba los hongos sagrados con un rodillo de piedra, tarea religiosa que solo podía desempeñar una mujer joven, muy posiblemente virgen para la molienda del hongo ${ }^{(2)}$

En época antigua consumían en público los hongos sagrados, dichas costumbres se encontraban en extremo difundidas y se practicaban en ceremonias públicas y no en lugares ocultos, como lo fue después de que los frailes españoles persiguieran aquellas prácticas profanas. Esa costumbre se practicaba de manera especial en las regiones Zapoteca, Nahua, Hñahñu (otomí), Mazateca, Chinanteca, Chatino, Mixe, mixteca Totonaca, Huasteca y $\operatorname{Tarasca}^{(2)}$.

El propio Hernán Cortés en 1537 realizó un juicio contra Mixcóatl, a quien se le acusaba de practicar la vieja religión por consumir nanácatl diabólico ${ }^{(24)}$.

En 1620 el Santo Oficio de la Inquisición decretó formalmente en la Ciudad de México que la ingestión de plantas embriagantes constituía una herejía. De hecho, la iglesia persiguió sin descanso los cultos enteógenos mexicanos. Fanáticos intolerantes como Hernando Ruiz de Alarcón llegaron incluso a torturar a chamanes indios en un intento de conseguir los secretos de sus "diabólicos" ritos.

Como respuesta a estas acciones execrables, el hongo se convirtió en el arcanum arcanorum, el "secreto de secretos" de esos pocos chamanes que continuaron con la práctica de antiguos ritos en áreas remotas. Con el paso de los siglos, el fanatismo de los frailes españoles se fue olvidando y sus misteriosos relatos pasaron a ser poco más que extravagantes curiosidades de una era pasada. Los modernos "evangelistas" de las fes protestantes han ocupado el lugar que dejó vacante la Iglesia Católica, librando una enérgica cruzada contra los hongos enteógenos. Tal como lo expresa un misionero de forma sucinta: "la ingestión del hongo divino plantea serios problemas al concepto" (35).

Ya en el siglo XVII los misioneros se vieron obligados a reconocer que no podían erradicar lo que para ellos era un acto de idolatría, motivo por el cual redactaron extensos manuales al objeto de poner en guardia a la iglesia contra las supersticiones y prácticas precristianas de los indígenas. Uno de ellos lleva por título "Tratado de las supersticiones y costumbres gentílicas que hoy viven entre los indios naturales de esta Nueva España".

Escrito en 1629 por Hernando Ruiz de Alarcón, resulta único no solo porque ofrece una relación completa del uso de las sustancias embriagantes entre los indígenas de los actuales estados de Guerrero y Morelos, sino que, además, se encuentra en náhuatl e incluye cánticos, conjuros y ensalmos que recitaban los chamanes, tanto para alejar el mal, como para sanar a un enfermo (ya fuera un simple dolor de muelas o alguna dolencia grave).

La obra escrita por Jacinto de la Serna, "Tratado de las supersticiones, idolatrías, hechicerías y otras costumbres de las razas aborígenes de México" (1656), narra como un curandero llamado Juan Chichitón, es decir perrillo, 
natural del pueblo de Tenango y "gran maestro en supersticiones", cometió una "gran idolatría" (una sesión chamánica) con unos "hongos que se recogen en el monte". Los antiguos sacerdotes tras permanecer prácticamente toda la noche en oración, al amanecer recogían estos hongos "pequeños y colorados" que eran considerados dioses por su efecto embriagador. A esta especie la llamaban Quautlan nanacatl.

Un buen día este curandero oficiaba entre un grupo de gente que se había congregado en honor de un santo católico, cuya imagen se encontraba en un altar junto a los hongos y un tazón de pulque; tras el ritual y los cánticos que duraron toda la noche ofreció a los participantes:

"comer de los hongos como á modo comunión y á beber del pulque, y rematar la fiesta con abundante cantidad de pulque: que los hongos por su parte, y el pulque por la suya los sacó de juizio, que fue lastima..."

Jacinto de la Serna hizo todo lo posible por capturar al sacrílego curandero, sin embargo, éste resultó ser demasiado astuto y escapó al castigo de la inquisición. En este caso la especie que alude al texto podría tratarse de Conocybe siligineoides, descubierto por primera vez por Roger Heim y Robert Gordon Wasson en México, y publicado su uso como parte del ceremonial Mazateca de Oaxaca, sorprendentemente, según Paul Stamets, desde su descubrimiento en 1956 no se ha publicado nada analizado o confirmado sus propiedades psicoactivas ${ }^{(11)}$.

En el Archivo General de la Nación se conservan constancias de las Audiencias del Santo Oficio de la inquisición donde consta entre otros casos, que varias personas del pueblo de Taximaroa, Michoacán, tomaron una bebida de nanacates para saber dónde estaba una mujer que había abandonado a su marido. En la parte correspondiente a "procesos de indios, idólatras y hechiceros" se reproducen los juicios contra indígenas que utilizaban los hongos para saber si habían de morir pronto, si serian ricos o pobres, si vendrían desdichas, o para tener otras revelaciones de origen sobrenatural por medio de dichos hongos ${ }^{(22)}$.

En la edición de 1840 del Códice Yanhuitlán, a cargo de Wigberto Jiménez Moreno y Salvador Mateos Higuera, se comenta que los indios:

"Habían tomado nanacates para invocar al demonio como lo hacían los antepasados, que es público y notorio que siempre cuando nos llueve o se cogen los maíces llaman al diablo y que cuando cogen los maíces hacen sus borracheras" (22).

La iglesia persiguió tenazmente el uso de plantas visionarias por considerarlo herejía. Se suponía que debido a esta represión religiosa el culto a los hongos sagrados había desaparecido por completo de tierras mexicanas ${ }^{(32)}$.
De acuerdo con antropólogo Aguirre Beltrán, los esclavos provenientes de África integraron diversas especies a sus propias prácticas. También los españoles las emplearon, directa o indirectamente, interponiendo a un criado o esclavo para realizar consultas adivinatorias. Así, el uso de especies como el ololiuhqui (Turbina corymbosa), el peyote (Lophophora williamsii), la hoja de la pastora (Salvia divinorum) o el teonanácatl (Psilocybe mexicana) fueron motivo de represión inquisitorial ${ }^{(41)}$.

Lo cierto es que en los tres siglos posteriores no tenemos prácticamente ningún dato acerca de este culto a los hongos, e incluso se llegó a dudar de la existencia de los mismos dentro de las ceremonias rituales, negando su existencia e identificándolos con el peyote ${ }^{(42)}$.

Todo parecía sepultado en el olvido. Las referencias a los hongos cesan en 1726. Los textos de los cronistas por algunos eruditos de nuestro siglo no los tomaron como objetos de estudio ni los relacionaron con el hecho de que todavía se usaran estos hongos en algunos lugares de México ${ }^{(39)}$. Guy Stresser-Péan encontró en el Archivo de México la carta de 1726, escrita por don José Lanciego, en la que se habla del consumo de hongos en la Sierra Baja Huasteca ${ }^{(24)}$.

La región mazateca, específicamente la zona alta, fue objeto de múltiples investigaciones como la emprendida por Frederick Starr a principios del siglo XX. Posteriormente, en la tercera década de ese mismo siglo, le siguieron Eunice Pike, así como el matrimonio de Florence y George Cowan, pertenecientes al Instituto lingüístico de verano (ILV), y reconocidos etnobotánicos como Blas Pablo Reko y Richard Evans Schultes. Igualmente, antropólogos como Irmgard y Robert J. Weitlaner, Jean Bassett Johnson, este último quien, en el verano de 1938, en Huautla, presenció y documentó una ceremonia de consulta con un viejo sabio que comió hongos y tiró maíz para conocer el estado de una persona enferma, familiar del equipo de expedición. Empero, ninguna pesquisa ha sido tan popular como la realizada por Robert Gordon Wasson, cuyas publicaciones despertaron el interés nacional e internacional por Huautla de Jiménez, Oaxaca ${ }^{(41)}$.

El mérito de haber señalado la persistencia de ceremonias rituales asociadas a los hongos sagrados de los Mazateca corresponde al botánico Richard Evans Shultes y el etnólogo Robert Weitlaner. E. Ev. Shultes que publicó a este respecto dos notas, en 1939 y 1940, revelando la determinación del hongo pretendidamente utilizado, Panaeolus sphinctrinus.

Valentina Pavlovna y Robert Gordon Wasson vivamente interesados por tales indicaciones, tuvieron suerte de obtener en 1953, de una misionera estadounidense, Miss Eunice P. Pike, detalles inéditos sobre el empleo, en la región de Huautla de Jiménez, de hongos alucinatorios y adivinatorios, utilizados durante ceremonias evidentemente muy semejantes a las que dejara transcritas Sahagún, pero notablemente modificadas por 
el rito católico. Los Wasson recogieron cuatro especies que se utilizaban con fines adivinatorios, creciendo en los pastos y en los campos de maíz: Psilocybe mexicana, propia de los boñigos de las vacas: Stropharia cubensis, la tercera semejante a la psilociba de los Estados Unidos, descrita por Murril bajo el nombre de caerulences, se le denomino mazatecorum; la cuarta lignícola, pertenecía al género Conocybe siligineoides ${ }^{(23)}$.

Existen diferentes clases de niños santos que se distinguen por la fuerza que poseen. Los más conocidos son los "derrumbe": Psilocybe caerulescens que nacen donde la tierra está desgajada, aparecen con la caída de un rayo y son los más fuertes; le siguen los "San Isidro": $P$ silocybe cubensis que crecen en el estiércol de las vacas; y por último, los "pajaritos": Psilocybe mexicana que brotan en el musgo y en los prados húmedos ${ }^{(41)}$.

Los mazatecos llaman a los hongos "nti-si-tho"; nti es un diminutivo de respeto y cariño; el resto de nombre significa "el que brota". María Sabina no utilizaba Psilocybe cubensis. Ella decía:

"Recojo el "niño que brota de la tierra" y veo a dios, lo veo brotando de la tierra".

Prefería el "derrumbe": Psilocybe caerulescens ${ }^{(44)}$.

Aunque el nombre de la especie cubensis parece relacionarlo con Cuba, no debe interpretarse como si fuese originario solamente de esa isla o del Caribe en general. Más bien, se le designó así porque fue descrito por primera vez en 1906 por Franklin Summer Earle, agrónomo y micólogo estadounidense quien lo halló en Cuba ${ }^{(13)}$.

En 1955, Robert Gordon Wasson y su amigo Allan Richardson redescubrieron la ceremonia de "velada" con hongos psilocíbicos. Wasson relató su experiencia con María Sabina, en un artículo publicado el 13 de mayo de 1957 en la revista Life ${ }^{(32)}$

Con meses de diferencia Valentina Pavlovna, publicaría para This Week Magazine, "I Ate the Sacred Mushroom", en donde relataba su experiencia en el consumo de hongos "sin la guía de un sabio" y acompañada por su hija ${ }^{(41)}$

María Sabina describe aquel encuentro a su manera:

"Cuando los extranjeros tomaron los niños santos conmigo, no sentí nada malo. La velada fue muy buena. Tuve visiones diferentes. Llegue a ver lugares que nunca había tenido imaginación de que existiesen. Llegue al lugar de origen de los extranjeros. Vi ciudades. Ciudades grandes. Muchas y grandes casas... después supe que Wasson había quedado maravillado... vino otras veces. Trajo a su mujer y a su hija. También vinieron personas diferentes con él" (30).

Y prosigue:
"Hay un mundo más allá del nuestro, un mundo invisible, lejano, pero también cercano. Allí vive dios, viven los muertos, los espíritus y los santos; es un mundo donde todo ha sucedido y todo se sabe. Ese mundo habla, tiene lenguaje propio. Yo repito lo que me dice. Los hongos sagrados me llevan y me traen al mundo donde todo se sabe. Son ellos, los hongos sagrados, los que hablan en una forma que yo puedo entender. Yo les pregunto y ellos me responden. Cuando regreso del viaje, digo lo que ellos me han dicho, me han mostrado" (44).

Gordon Wasson no sólo desobedeció la advertencia de María Sabina de no mostrar a nadie las fotografías tomadas en la velada, sino que publicó en la revista Life el reportaje: "Culto a los hongos sagrados". Esto provocó que la prensa vulgarizara la noticia y con ello la invasión de hippies a las montañas oaxaqueñas.

María Sabina narra:

"En cierto tiempo vinieron jóvenes de uno y otro sexo, de largas cabelleras, con vestiduras extrañas. Vestían camisas de variados colores y usaban collares. Vinieron muchos. Algunos de estos jóvenes, me buscaban para que yo me desvelara con el pequeño que brota. "Venimos a buscar a dios", decían. Para mí era difícil explicarles que las veladas no se hacían con el simple afán de encontrar a dios, sino que se hace con el propósito único de curar las enfermedades que padece nuestra gente. Estos jóvenes, rubios y morenos no respetaron nuestras costumbres. Nunca, que yo recuerde, los niños santos fueron comidos con tanta falta de respeto. Para mí no es un juego hacer veladas. Quien lo hace para sentir simplemente los efectos, puede volverse loco y quedar así temporalmente. Nuestros antepasados siempre tomaron los niños santos en una velada presidida por un sabio" (12).

En el verano de 1969 el ejército mexicano y agentes federales intervinieron en Huautla para expulsar a los jóvenes, extranjeros y mexicanos. Dice el mismo Álvaro Estrada que el "comportamiento de los jóvenes mexicanos, entre los que se encontraban delincuentes y no pocos "niños ricos" en busca de aventuras, fue lamentable". Cuando Wasson conoció a María Sabina, ella aún usaba una cuarta clase de hongo, que nombraba en mazateco como "Ya'nte", y que crecía sobre la madera de un árbol muerto; Wasson lo identificó con el Conocybe siliginoides, especie que hoy se encuentra extinguida ${ }^{(30)}$.

Al final de su vida María Sabina lamentó la pérdida definitiva del poder divino de los hongos:

"Desde el momento en que los extranjeros llegaron a buscar a dios, los niños santos perdieron su pureza. Perdieron su fuerza, los descompusieron. De ahora en adelante ya no servirán" ( ${ }^{30)}$. 


\section{Agradecimientos}

Expreso mi más profundo agradecimiento la Dra. Leticia Romero Bautista, profesora investigadora del Centro de Investigaciones Biológicas del Instituto de Ciencias Básicas e Ingeniería (ICBI) de la Universidad Autónoma del Estado de Hidalgo, por su colaboración en la realización de la introducción para esta revisión. A mis alumnas por su dedicación y esfuerzo, sin ustedes no hubiera sido posible este artículo.

\section{Referencias}

[1] Alucinógenos del México Prehispánico. Arqueología Mexicana. 2003; (23, 28, 38-41): 16.

[2] Becerra D. Las setas y los hongos en el mundo antiguo. 1era ed. Las Palmas de Gran Canaria: Anroart; 2007

[3] Benítez F. Los hongos alucinantes. 1st ed. México, D.F.: Ediciones ERA; 2005.

[4] Brusco R. Alucinógenos del pasado: la fascinante historia de los hongos mágicos [Internet]. Ancient Origins España y Latinoamérica. 2017 [cited 10 August 2019]. Available from: https://www.ancientorigins.es/noticias-general-historia-tradicionesantiguas/alucin\%C3\%B3genos-pasado-la-fascinante-historia-loshongos-m\%C3\%A1 gicos-004013

[5] Cabrera S. Nanacatl, los hongos sagrados [Internet]. komoni.chemisax.com. 2016 [citado 6 Agosto 2019]. Disponible en: https://komoni.chemisax.com/nanacatl-los-hongos-sagrados/

[6] Carod-Artal F. Alucinógenos en las culturas precolombinas mesoamericanas. Neurología. 2011; 30(1):42-49.

[7] Códices aztecas [Internet]. Todolibroantiguo.es. 2013 [citado 10 Agosto 2019]. Disponible en: http://www.todolibroantiguo.es/librosraros/codices-aztecas-codex-boturini-mendoza-florentinomagliabechiano-tira-peregrinacion.html

[8] Códice Magliabecchiano [Internet]. Es.wikipedia.org. 2019 [cited 12 August 2019]. Available from: https://es.wikipedia.org/wiki/C\%C3\%B3dice_Magliabecchiano

[9] Contreras A. La Sistemática. 1st ed. Pachuca, Hgo.: Universidad Autónoma del Estado de Hidalgo; 2007.

[10] Cruz Bárcenas A. Tláloc sigue enterrado aquí; se llevaron a Chalchiuhtlicue: Guadalupe Villarreal. La Jornada [Internet]. 2019 [cited 10 August 2019]::8. Available from: https://www.jornada.com.mx/2014/04/05/espectaculos/a08n1esp

[11] De la Serna J. Tratado de las supersticiones, idolatrías, hechicerías, y otras costumbres de las razas aborígenes de México - Biblioteca Virtual Miguel de Cervantes [Internet]. Cervantesvirtual.com. 2019 [citado 10 Agosto 2019]. Disponible desde: http://www.cervantesvirtual.com/servlet/SirveObras/01593963546705 955212257/p0000002.htm\#29

[12] Estrada A. Vida de María Sabina, la sabia de los hongos. 1st ed [México]: Siglo XXI; 1977.

[13] Furst P. Los Alucinógenos y la cultura. 1st ed. México: Fondo de Cultura Económica; 1980.

[14] González J. Eva y la manzana. Revista murciana de antropología. $1995 ;(2): 17-39$.

[15] Guzmán, G. La diversidad de los hongos en México.1995;(39): 52-56
[16] Guzmán G. Las especies de Psilocybe (Fungi, Basidiomycotina, Agaricales) conocidas de Jalisco (México) y descripción de dos nuevas para la ciencia. Acta Botanica Mexicana. 1998;(43):23-32.

[17] Guzmán G. Species Diversity of the Genus Psilocybe (Basidiomycotina, Agaricales, Strophariaceae) in the World Mycobiota, with Special Attention to Hallucinogenic Properties. International Journal of Medicinal Mushrooms. 2005; 7(1-2):305-332

[18] Guzmán, G. El uso tradicional de los hongos sagrados: pasado y presente. Etnobiología. 2011; 9 (1):1-19.

[19] Guzmán, G. New taxonomical and ethnomycological observations on Psilocybe s., from Mexico, Africa and Spain. Acta Botánica Mexicana 2012; (100): 81-106.

[20] The Health Officers Council of British Columbia. Public Health Perspectives for Regulating Psychoactive Substances. Vancouver: The Health Officers Council of British Columbia; 2011.

[21] Hernández-Santiago Faustino, Martínez-Reyes Magdalena, PérezMoreno Jesús, Mata Gerardo. Pictographic representation of the first dawn and its association with entheogenic mushrooms in a 16th century Mixtec Mesoamerican Codex. Rev. Mex. Mic [revista en la Internet]. 2017 [citado 2019 Ago 05] ; 46: 19-28. Disponible en: http://www.scielo.org.mx/scielo.php?script=sci_arttext\&pid=S018731802017000200019\&lng=es.

[22] Herrera T. De los que saben de Hongos. Ciencias [Internet]. 1992 [consultado el 10 de agosto de 2019]; (28): 37-40. Disponible en: https://www.revistaciencias.unam.mx/pt/177-revistas/revista-ciencias28/1711-de-los-que-saben-de-hongos.html

[23] Historia del descubrimiento de los hongos alucinógenos de mexico | Onirogénia [Internet]. Onirogenia.com. 2011 [citado el 10 Agosto 2019]. Disponible desde: http://www.onirogenia.com/enteogenos/historia-del-descubrimientode-los-hongos-alucinogenos-de-mexico/

[24] Hongos de México. Arqueología Mexicana, 2019; (15, 16, 50):48

[25] Ixchel Balam. (20, Mayo, 2018).Los mexihkas no creían en dioses. Disponible en: https://m.facebook.com/story.php?story_fbid=441987102894033\&id= 100012482410764 [Consultado el 2019, Agosto, 10]

[26] Kirk P, Cannon P, Minter D, Stalpers J. Dictionary of the fungi. 10th ed. United Kingdom: CABI; 2008.

[27] López García Alexanders, Jiménez-Ruiz Mario, Pérez-Moreno Jesús. Vocablos relacionados con el recurso micológico en el idioma de la cultura chinanteca de la Sierra Norte del estado de Oaxaca, México. Rev. Mex. Mic [revista en la Internet]. 2017 [citado 2019 Ago 05]; 46: 9$18 . \quad$ Disponible en: http://www.scielo.org.mx/scielo.php?script=sci_arttext\&pid=S0187$\underline{31802017000200009 \& \operatorname{lng}=\mathrm{es}}$

[28] López J. Los alucinógenos. 1era ed. Madrid: Editorial CSIC Consejo Superior de Investigaciones Científicas; 2017.

[29] López Noreña G. El libro y el bios. 1ª ed. S 1: eumed.net; 2010

[30] Los Niños Santos de María Sabina [Internet]. El Santuario del Alba. 2013 [consultado el 10 de agosto de 2019]. Disponible en: https://santuariodelalba.wordpress.com/2013/12/05/maria-sabina-i/

[31] Marín G. Historia verdadera del México profundo. Oaxaca: EDUCAYOTL A.C; 2013.

[32] Méndez M. Psicofármacos y Espiritualidad: La Investigación con Sustancias Psicodélicas y el Surgimiento del Paradigma Transpersonal. Journal of Transpersonal Research. 2013; 5(1):36-57.

[33] Motolinía T, Esteva Fabregat C. Historia de los indios de la Nueva España. Madrid: Historia 16; 1985.

[34] Oberwinkler F. Evolutionary trends in Basidiomycota. Stapfia. 2012; 96: 45-104. 
[35] Ott J. Psilocibina / psilocina / baeocistina: el grupo del teonanácatl. En: Ott J, ed. por. Pharmacotheon: Drogas enteógenas, sus fuentes vegetales y su historia. 2da ed. España: La liebre de marzo; 2015. p. 270-310.

[36] P. E. El espíritu del hongo - el culto etnomicológico de Tassili. [Internet]. Fungicosmos.wordpress.com. 2018 [citado 10 Agosto 2019] Disponible dese: https://fungicosmos.wordpress.com/2018/03/31/elespiritu-de-la-seta-el-culto-etnomicologico-de-tassili/

[37] Pérez-Ochoa Mónica L., Chávez-Servia José L., Vera-Guzmán Araceli M., Aquino-Bolaños Elia N. y Carrillo-Rodríguez José C. (14 de diciembre del 2018). Medicinal Plants Used by Indigenous Communities of Oaxaca, Mexico, to Treat Gastrointestinal Disorders, Shagufta Perveen y Areej Al-Taweel, IntechOpen, DOI: 10.5772 /intechopen.82182. Disponible en: https://www.intechopen.com/books/pharmacognosy-medicinalplants/medicinal-plants-used-by-indigenous-communities-of-oaxacamexico-to-treat-gastrointestinal-disorders

[38] Ramírez-Cruz V, Guzmán G, Villalobos-Arámbula A, Rodríguez A, Matheny P, Sánchez-García M et al. Phylogenetic inference and trait evolution of the psychedelic mushroom genus Psilocybe sensu lato (Agaricales). Botany. 2013; 91(9):573-591.

[39] Reyes L. Una relación sobre los hongos alucinantes. Tlalocán. 1970; 6(2):141.

[40] Rodríguez Arce José M, Arce Cerdas Marco A. Ritual consumption of psychoactive fungi and plants in ancestral Costa Rica. Journal of $\begin{array}{llll}\text { Psychedelic Studies. } & 2019 & \text { Disponible en: }\end{array}$ https://doi.org/10.1556/2054.2019.010

[41] Rodríguez C. Mazatecos, niños santos y güeros en Huautla de Jimenez, Oaxaca. 1era ed. Ciudad de México: Universidad Nacional Autónoma de México; 2019.

[42] Safford, W.E Narcotic plants and stimulants of the ancient Americans. 1st ed. Washington: Annual Report of the Smithsonian Institution; 1916.

[43] Sánchez-García, M., \& Guzmán-Dávalos, L. (2013). Phylogenetic inference and trait evolution of the psychedelic mushroom genus Psilocybe sensu lato (Agaricales). Botany, 91(9), 573-591

[44] Schultes R, Hofmann A. Plantas de los dioses. 2nd ed. México, D.F.: Fondo de Cultura Económica; 2000.

[45] Serrano D. La psilocybina: Perspectiva histórica y farmacológica e investigaciones actuales autorizadas. Revista cultura y droga. 2009; 16(14):165-188.

[46] Wasson G. El hongo maravilloso teonanácatl. Medellín: Fondo de Cultura Económica; 1993. 